\title{
The need for pediatric indoor physical training guidelines during COVID-19 pandemic-related lockdown: where do we stand?
}

\author{
Thirunavukkarasu Arun Babu ${ }^{1}$ (D) \\ Received: 8 January 2022 / Revised: 8 January 2022 / Accepted: 21 January 2022 / Published online: 31 January 2022 \\ (c) The Author(s), under exclusive licence to Springer-Verlag GmbH Germany, part of Springer Nature 2022
}

Keywords COVID-19 $\cdot$ Children · Fractures $\cdot$ Physical $\cdot$ Training $\cdot$ Sports

We read the article titled "Decreases in pediatric fractures during the COVID-19 pandemic - a nationwide epidemiological cohort study" published by Zacay et al. with interest [1]. Authors have conducted a nationwide epidemiological cohort study and found that there was significant decrease in traumatic fracture rate in children when compared to the previous 5 years in Israel.

Ever since the pandemic broke out, most countries have adopted the strategy of enforcing varying degrees of lockdown to curb coronavirus disease 2019 (COVID-19) pandemic [2]. Schools across the globe suspended physical classes and switched to Internet-based remote learning. Most children were forced to stay indoors because of lockdown, which had considerably disrupted their routine [3]. Restriction of movement, inability to indulge in physical outdoor sports activities, and reduced social contact with peers could have played a role in reducing the incidence of fractures in pediatric age during lockdown. As expected, this effect was maximum in adolescent age group who were significantly affected due to lockdown. The incidence of fractures in children under 3 years had not changed much because they often stay indoors most of the time. Reduced incidence of fractures directly implies that children indulged in lesser than usual physical activities. Moreover, the monotonous daily routine and difficulty to engage in outdoor physical and sports activities can have a negative bearing on the psychosomatic wellbeing of the child [3].

Though findings of the study are as expected, it also indirectly underscores the need for evidence-based guidelines for indoor physical training and sports activities for children

Communicated by Peter de Winter

Thirunavukkarasu Arun Babu

babuarun@yahoo.com

1 Department of Paediatrics, All India Institute of Medical Sciences (AIIMS), Mangalagiri, Andhra Pradesh, India during COVID-19 lockdown period. It is very vital to look into this area and recommend ideal indoor physical training that would be needed for children of various age groups during COVID-19-related lockdown in the future.

Author contribution TA conceived the concept and drafted the manuscript.

Availability of data and material Yes, available with the study team.

\section{Declarations}

Ethics approval Not applicable.

Consent to participate Not applicable.

Consent for publication Not applicable.

Conflict of interest The author declares no competing interests.

\section{References}

1. Zacay G, Modan-Moses D, Tripto-Shkolnik L, Levy-Shraga Y (2022) Decreases in pediatric fractures during the COVID-19 pandemic - a nationwide epidemiological cohort study. Eur J Pediatr. https://doi.org/10.1007/s00431-021-04323-5. Epub ahead of print

2. Shankaralingappa A, Thirunavukkarasu AB (2021) Pathogenesis of COVID-19 and multi-system inflammatory syndrome in children. Int J Contemp Pediatr 8:777-781. https://doi.org/10.18203/ 2349-3291.ijcp20211096

3. Babu TA, Selvapandiyan J (2020) The psychological effects of COVID-19 pandemic related lockdown in children. Indian Pediatr 57:1087. https://doi.org/10.1007/s13312-020-2053-X

Publisher's Note Springer Nature remains neutral with regard to jurisdictional claims in published maps and institutional affiliations. 